\title{
Xi'an Practical Implementing, Training Issues, and Improvement Strategies of Bilingual Primary Education
}

\author{
Qing WEI \\ Xi'an University \\ Xi'an,710065, China
}

\begin{abstract}
-currently our current bilingual education teacher has the low quality of the ranks; it is difficult to meet the needs of qualified pre-school bilingual education. The teachers of the current bilingual education should have the science right preschool bilingual educational philosophy and strong multiexpertise structure of pre-school bilingual teaching ability. They should meet certain academic requirements by constructing objects, clearly structure training in the form of flexible network with the Bilingual Teacher Training mode, and enhance teachers' professional self-reflective ability, which can effectively promote bilingual pre-school teachers' professional development, improve our quality pre-school bilingual education.
\end{abstract}

Keywords- Bilingual Preschool Education; Preschool Bilingual Teachers; Specifications; Professional Development

\section{INTRODUCTION}

Complex investigation has found that the current bilingual teaching kindergarten through better understanding of our market, it further confirms the current bilingual textbooks diverse but uneven situation. Each has its own textbook and certain theoretical support in the appropriate teaching mode. For example, some have the alphabetical order based on some common children's lives from the familiar things proceed. According to the word itself, some difficulty has the degree of orchestration, eventually, and the numbers of repetitions are in contact with children, you can use some opportunities to consider, and so on. Some materials need teachers after training system in order to truly understand and master. Moreover, each of the materials also has different specific adaptation if materials need to arrange for a long time to "soak" to complete. And some just have a subject of learning content. Some teachers use textbooks with only version, some books are both teachers, and parents of young children and even books.Some textbooks only arrange centralized activities; some textbooks also arranged games, extension activities, etc., such numerous and less unity, in its own way lack of highly authoritative status. Making bilingual education has just started; many immature kindergartens are confused (parents equally confused). There are the face of rising home sales and a lot of publicity of various materials, which one is better, it is difficult to select, at a loss thus resulting in a larger current arbitrariness and blindly follow the trend phenomenon in materials use. At the same time, short-term training is difficult to fully grasp the whole system of teaching materials, so even choose a good teaching, there is no guarantee that it is correct and standardizes the use.

\section{A SERIOUS SHORTAGE OF QUALIFIED BILINGUAL TEACHERS}

Qualified bilingual pre-school education teachers should have the basic ability in two aspects. First, they should know the psychological development of children and the rules and characteristics, develop educational programs based on education and early childhood development objectives, select educational content, adopt lively education organization activities, and promote the comprehensive development through bilingual education programs for children quality.The second is to have a more solid foundation in English, they should be able to use the correct specification of the voice demonstration, rich vocabulary and grasp randomly applied flexibly, to understand the cultural background of English-speaking countries, customs, traditions, and so on.

\section{CAUSES OF ShORTAGE OF TEACHERS IN BILINGUAL EDUCATION KINDERGARTEN}

In recent years, many kindergarten bilingual pre-school educations have made some achievements, but there are also a lot of problems, chief among them is the problem of teachers. First, the number of pre-school bilingual education teachers is unable to meet the needs of pre-school bilingual education generally carried out; the second is the level of bilingual education for pre-school teachers that is not satisfactory, unable to meet the needs of pre-school bilingual education effectively carried out. Qualified kindergarten teachers are scarce in bilingual education. One of the reasons is that pre-commitment system has infant normal or kindergarten teachers training college task.Due to historical reasons, they are in the last ten years; there is the lack of preschool training Bilingual teachers' goals and plans.For a long time basically, they did not offer compulsory English, and also the starting point for most of the students enrolled is in junior high class, so this is caused by the current kindergarten teachers' capable of teaching English of shortage of reasons for early childhood activities. For the existence of this situation, in order to continue to meet the demand of the market economy preschool bilingual education, teachers in recent years, in some kindergarten teachers' training school should strengthen the students to learn the basics of English and applications. We should be actively stepping up to the pre-school bilingual culture new faculty research and education goals. In addition, we should 
actively explore a new model train bilingual education for pre-school teachers and new ways to take the initiative to adapt to the culture of social, economic, cultural and educational development of children. Let the children adapt teachers, and schools in some places with new bilingual teachers cultivating research has achieved a certain experience, bilingual education for the majority of kindergarten teachers is to provide a guarantee. However, things like the exploration and study of the problem of preschool bilingual education teacher quality and capacitybuilding, etc. are also rare, and this requires us to actively take the initiative to study, in practice, we should constantly improve.

\section{The BILINGUAL EdUCATION TEACHERS SHOULD HAVE THE QUALITIES AND ABILITIES}

The five-year pre-school bilingual education teachers compared with the pre-professional teachers, more enhance requirements for English proficiency, so we train and select for special training to improve students qualified bilingual pre-school education of new teachers in the students. Its purpose is to ensure the quality of kindergarten bilingual education, focusing on early childhood teaching basic scientific and effective. Good early childhood training in language and customs, the standard pronunciation can improve children's interest in bilingual learning and the teachers should undertake responsibility of bilingual. Therefore, in the pre-school bilingual education teachers, they should first be a qualified with early childhood teachers, the possible training become qualified bilingual teachers.

\section{The GoAls of Bilingual EdUCATION TEACHER TRAINING IN PRE-SCHOOL}

Target training of personnel in the new period reflects the general requirements of the national and social development, and it is the main basis for the development of pre-school bilingual education of teacher training objectives. The preschool bilingual education teacher-training goal is the new era of the specific training objectives. How will research construct knowledge taught as the basis for capacity building as fundamental to improve the overall quality for the purpose of knowledge of the Trinity, preschool bilingual education teacher capacity and quality of the training objectives to study? So that pre-school bilingual education teacher training reflects the following characteristics: Features bilingual teachers have outstanding talents times before, forwardlooking, innovative science, bilingual education reflects preprofessional requirements and general characteristics of the organic combination, taking into account the overall development of students and the healthy development of personality characteristics into account.

\section{MAKE BILINGUAL EdUCATION INTO LIFE: LESSONS FROM THEORY OF LIFE EDUCATION}

From the theory of life education, physical and mental development characteristics of pre-school children determine their learning objectives, content, which is related to the lives of children, life is the content of early childhood education, child life is children's education, and they are learning from life, what kind of life is What kind of education is affected. If we live with each other in early childhood education and childcare fragmentation, child education is as something other than life, and then early childhood education will be due to children living away from failure. Reality proves linked with social life, in line with the education of children in need that has the vitality. Tao Xingzhi's life of pre-school education theory bilingual education objectives, content, ways and means have a profound inspiration.

\section{A. 1 Make educational goals into life.}

The interdependence of language and life as a means and tools to exchange information on the daily life of bilingual education must return to life. The ultimate goal of bilingual pre-school education is to help children initially use Chinese and English to express their ideas and aspirations in life to communicate thoughts and feelings with others, while promoting children's social adaptation and development in other areas.

Many activities are organized in bilingual kindergarten classroom teaching methods directly to apply in our primary and secondary schools, as a lesson to teach the English. The school starts with the word reciting, sentence writing and practice. This life from early childhood learning will inevitably lead to inefficient bilingual education. Language is the daily life of the most frequently used tool, its biggest feature is AC applications, and the child's language is developed in the process of applying. Children actively use only English and others to exchange ideas or to express their ideas in the process, in order to truly learn and master the English language.

\section{B. Modest Academic Requirements is the Obstacle of Bilingual Pre-school Teachers' Professional Development}

To ensure the quality of bilingual education, bilingual education in pre-school teachers should have higher education levels in view of the former bilingual preschool education institutions specializing in the process of being built.There is no bilingual education professional training uniform specifications and standards, so it is necessary for teachers to make certain academic requirements on the basis of academic status before the current bilingual teachers on the analysis of the actual demand before the current bilingual education.Our pre-school bilingual teacher qualifications should have the following requirements. The qualified preschool bilingual teachers should achieve two English professionals with preschool education specialist professional level. While teachers in the office should through continuing education and other ways continuously improve their degree of specialization in the four former school teacher professional development of bilingual preschool bilingual education that is the a particular area. China's pre-school bilingual teachers in terms of quantity and quality terms are far from meeting the needs of pre-school bilingual education, therefore, on the basis of pre-school 
bilingual teachers, they should meet the professional qualifications standards, to promote pre-school bilingual teacher professional development research and explore ways to have some forward-looking and practical significance.

Enhance teachers' ability to reflect the professional ability. In teachers' professional development, teachers' selfdevelopment dominated the teachers of self-development and self-development training that differs from culture.I want to develop the former; the latter is to develop teachers' selfdevelopment. It is the result of teachers' autonomy professional and self-reflection to obtain the ability to form the extent of influencing teachers' selfdevelopment.Therefore, we believe that the promotion of pre-school bilingual teacher self-development, essentially to promote the formation of independent teachers' ability to reflect and grow as a reflective practitioner due to the context of education.

\section{Strengthen Professional Learning English, Emphasize Practice and Training, Promote the Improvement of Vocational Teachers and the Child's Ability in the Bilingual Education.}

Young teachers are a good pre-school and bilingual education teacher resources, preschool bilingual education reserves force and force. Improving the professional standards of young English teachers and students on the basis of qualified early childhood teacher training is one of the important ways to train bilingual kindergarten teacher. To achieve this goal, the school level, of the case can be taken to some of the specific practices.Increase hours per week and expand compulsory English course content, teaching content should open hearing, speech, speaking class with a single prominent text understanding and practice, reading and writing multi-channel learning, listening, speaking, reading, and it can comprehensively improve the English proficiency of young teachers and students.

Set up Additional electives. Electives focus on expanding students' knowledge, emphasizing student initiative to gain experience and develop interest and expertise, which can offer English, English Literature Class, English Grading remedial classes, bilingual pre-school design theme activities and other research. Teachers guide children to establish the scientific concept of pre-school bilingual education. Studies have shown that pre-verbal stage is the critical period of learning the mother tongue. People do not like learning a second language as first language learning that has a particularly critical period of development, although the second language learning will bring people a role in promoting development. We should recognize the value of children's English language development and other aspects of development, but not blindly exaggerate the significance of learning English. Especially since China is not "balanced" in the bilingual education or bilingual learning environment for preschool children --- Mandarin language learning should be no doubt in the first language of education. Any influence of the development of children's mother tongue and second language education programs for children are likely to lead to the development of serious mistakes. I believe that the English pre-school children's educational objectives should be: first, children develop an interest in learning English, improve the use of language to interact. Second, it is to help children build a sense of initial English voice, increase their language sensitivity

\section{CONCLUSIONS}

After the pre-service training and Job Training forging professional vocational training, it is another model of bilingual education for pre-school professional training, and it refers to in-service teachers for kindergarten, a preschool kindergarten teacher that is the background of preschool teacher training and English speaking backgrounds. After the pre-vocational education and vocational training, a professional integration is the inevitable trend. Integration is prompting preschool teachers' listening, speaking and other skills through intensive English training, it helps them master the English language knowledge; improve their English proficiency, so that we can get "preschool teacher has English transformation." On the other hand, the integration of early childhood teachers can make the background of early English professional have knowledge and skills to master the preschool skills, preschool workers become a member of the so-called "English teachers of early childhood education." Pre-employment and post-secondary vocational education is in close connection to the professional development of teachers. To create outstanding talent preschool bilingual education has a strong thrust. In short, the pre-school bilingual education in China has just started, and study of the professional bilingual preschool teacher training is at the exploratory stage, there are many problems waiting for us to ponder and research. We enhance the professional construction; we should strive to explore more mature, more effective talent to develop new models, social services, services of pre-school bilingual education.

Acknowledgements:

Fund Project: This paper is Xi'an Social Fund Project 13WL01 results.

\section{References}

[1] Dan Yao, Li Zhanghua. Research and Exploration former preschool bilingual professionals in vocational education training mode $[\mathrm{J}]$ Hubei Adult Education Institute, 2010,02: 8-10.

[2] Chen Xuemei, Zhao Fang. Bilingual education preschool teacher specifications and professional development [J] pre-study, 2010,05: $39-43+49$.

[3] Liu Ying, TianXingjiang, KuiFeng. Practice Xinjiang Preschool Bilingual Education in the public interest perspective $[\mathrm{J}]$ pre-study, 2011,12: $13-17+51$.

[4] Zhang Shushan.Focusing on early childhood learning characteristics of language to promote the healthy development of "bilingual" teaching coordination $[\mathrm{J}]$ Language and Translation, 2007,03: 11.

[5] Luo Yunping, Lu Wei.Bilingual pre-school education status quo Investigation and Reflection [J] pre-study, 2003,06: 21-22. 